\title{
Effects of Exercise on The Knee Joint in an Experimental Rheumatoid Arthritis Model
}

\author{
Morgana Neves, ${ }^{1}$ Alana Ludemila de Freitas Tavares, ${ }^{1}$ Ana Caroline Barbosa Retameiro, ${ }^{3}$ Aline Reginato, ${ }^{2}$ Taciane Stein da \\ Silva Leal, ${ }^{1}$ Lucinéia de Fátima Chasko Ribeiro, ${ }^{3}$ Gladson Ricardo Flor Bertolini ${ }^{1}$
}

${ }^{1}$ Physiotherapist - Universidade Estadual do Oeste do Paraná - Unioeste - Cascavel, PR, Brazil

${ }^{2}$ Physiotherapy Academic - Universidade Estadual do Oeste do Paraná - Unioeste - Cascavel, PR, Brazil

${ }^{3}$ Biologist - State University of Western Paraná - Unioeste - Cascavel, PR, Brazil

\section{Disclose and conflicts of interest: none to be declared by all authors}

\section{ABSTRACT}

Introduction: The initial inflammatory events of rheumatoid arthritis (RA) denote a synovitis process. An inflammatory cascade affects the synovial fluid, synovial membrane, joint cartilage and bone tissue. The maintenance of joint tissue in the disease is aimed at self-management of the joint, as treatment physical exercise can assist in inflammatory modulation. The objective of the study was to evaluate the effects of exercise on the joint tissue of rats submitted to experimental rheumatoid arthritis.

Materials and Methods: 64 male Wistar rats were divided into two acute and chronic inflammatory periods, and subdivided into four groups: CG: control group, CEG: exercise control group, GL: injury group and LEG: exercise injury group. The animals were submitted to rheumatoid arthritis simulation after two inoculations containing Freund Complete Adjuvant (CFA), one intradermal and one at the tibiofemoral joint. As a treatment protocol, the animals of CEG and LEG were submitted to climbing exercise on stairs with an overload of 100 grams coupled to the tail of the animal. The morphological aspects of the knee joint were analyzed.

Results: It was verified that the animals of CG and LEG showed normal parameters of the articular cartilage of femur and tibia, synovial membrane and bone periarticular region. The LG animals presented histological alterations characteristic of inflammatory process and tissue degeneration. The animals of LEG, treated with exercise denote remodeling of joint tissue.

Conclusions: It is concluded that exercise shows beneficial effects of tissue recovery of the knee joint and periarticular bone tissue of rats submitted to an experimental rheumatoid arthritis model.

Keywords: Rheumatoid Arthritis; Morphology; Rehabilitation; Exercise.

\section{Introduction}

Rheumatoid arthritis (RA) is classified as an inflammatory disease with a pronounced algic picture which results in limited physical functioning. In addition to the symptoms of joint inflammation, fatigue and malaise can be associated with ${ }^{1}$. Due to pain and recurrence of symptoms, the individual with RA tends to avoid physical exercise, leading to reduced muscle strength, aerobic capacity and inactivity ${ }^{2}$.

The initial inflammatory events of the disease denote a synovitis process. An inflammatory cascade affects the synovial fluid, and cytokines migrate to the synovial membrane that responds to the process with cell hyperplasia, joint cartilage showing erosions and altered periarticular bone tissue ${ }^{3-6}$. The loss of joint cartilage in the RA is evident with narrowing of the joint space, thus favoring the loss of joint functional capacity ${ }^{7}$.

The lesions that occur in the RA, a systemic autoimmune disease, have as signs the destructive and chronic synovitis, with degradation of diarthrodial joints. Animal models that can simulate the aspects of RA pathogenesis in humans are an important tool in the investigation of the harmful mechanisms and possible rehabilitative actions ${ }^{8}$.

The treatment of the RA is composed of behavioral therapies, in order to promote self-management of joint protection, together with the pharmacological approach. Physical exercise is a therapeutic modality used for treatment and prevention of joint degeneration $^{9}$. The restriction of physical exercise to individuals with RA is related to worsening of joint symptoms, in this sense, the practice is related to the improvement of functionality and control of the evolution of the disease $\mathrm{e}^{10}$. In addition, exercise helps to maintain movement, promotes reduction of joint stiffness, improves intra-articular synovial fluid, thus promoting cartilage nutrition and regeneration of this structure ${ }^{11}$.

The effects of exercise on functional recovery and control of migration of inflammatory cells in the RA are known ${ }^{12}$, but little is known about the actions of exercise and treatment parameters in the joint tissue qualitatively in acute and chronic periods of the disease. Given the above, the objective of the study was to evaluate the effects of exercise on the joint tissue of rats submitted to experimental rheumatoid arthritis. 


\section{Materials and Methods}

\section{Animals}

The study is characterized as experimental and randomized, composed of 64 male Wistar rats, aged 15 weeks, weight 250 \pm 19 grams, kept in polypropylene plastic boxes, with access to water and ad libitum feed, controlled temperature at $21^{\circ} \mathrm{C} \pm 1^{\circ}$, photo light/ dark period of 12 hours. This study was approved by the Ethics Committee on Animal Use (CEUA) of the State University of Western Paraná.

After one week of acclimatization, the animals were randomly separated in two experimental inflammatory periods: acute with 7 days of inflammation, and chronic 28 days. In each group 32 animals were randomized and subdivided into 4 subgroups with $\mathrm{n}=8$. These were the animals: $\mathrm{CG}$ : control group, LG: injury group, CEG: exercise control group and LEG: exercise injury group (Figure 1).

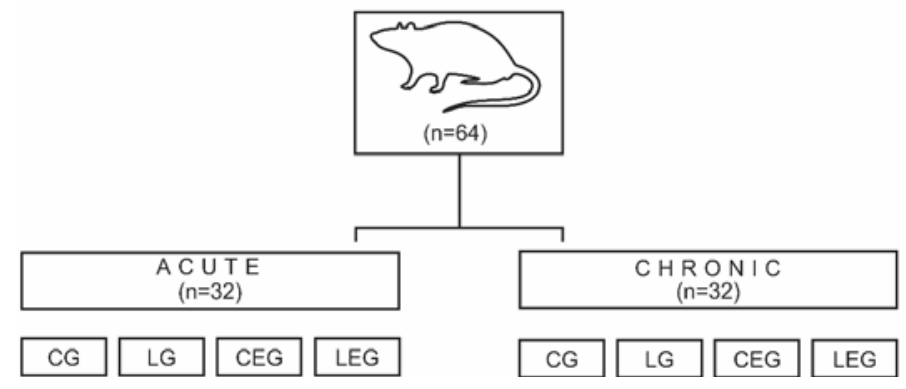

Figure 1. Schematization of sample groups.

Source: Author

\section{Drugs and reagentes}

The following substances were used: Freund Complete Adjuvant (CFA) containing Mycobacterium butyricum $\left(0.5 \mathrm{mg} / \mathrm{ml}\right.$, Difco $\left.{ }^{\circledR}\right)$, isotonic solution of sodium chloride $\left(0.9 \%\right.$, Aster $\left.{ }^{\circledR}\right)$, iodinated alcohol $(1 \%$, Rialcool $\left.^{\circledR}\right)$, ketamine hydrochloride (Ketalar - Brazil, 95 $\mathrm{mg} / \mathrm{Kg}$ ), xylazine (Xilazin - Brazil, 12 mg/Kg).

\section{Experimental procedure}

The animals were inoculated with two specific reagents, the first by intradermal injection at the base of the tail containing $50 \mu \mathrm{l}$ CFA for the LG and LEG groups, and sodium chloride for the CG and CEG animals. Pre-sensitization is the first systemic contact of the bacterium with the animal's immune system. The administration area of the substance was trichotomized and submitted to asepsis of the injection site with iodinated alcohol. The substance was then administered with the aid of a $1 \mathrm{ml}$ syringe and $13 \times 4.5 \mathrm{~mm}$ needle.

The second inoculation consists of an intraarticular injection, performed in the tibiofemoral joint seven days after the intradermal injection. For this, the animals were submitted to trichotomy of the anterior face of the right knee, in triple flexion positioning of the right pelvic limb to apply the substance intraarticularly.

\section{Treatment protocol}

As a treatment protocol, the resisted climbing exercise on stairs was adopted. The animals of CEG and LEG were adapted to the ladder prior to the start of the experiment. A vertical wooden ladder was used, with 67 iron steps, height $1.18 \mathrm{~m}$, width $20.5 \mathrm{~cm}$ and inclination $60^{\circ}$. At the top of the staircase, a 20x20 cm high and wide box was positioned, with the purpose of resting the animals in the intervals between the series.

For the animals of the acute inflammatory period, we used a 4-day treatment protocol on interspersed days, with 4 series of 5 rises and a 60-second interval between the series, and an overload of 100 grams adapted to the animals' tails. The beginning of treatment was 24 hours after intra-articular injection.

The animals of the chronic inflammatory period, in the first week performed 4 series of 5 rises, with interval and overload equal to the acute group, however there was an increase in the rise overload during the experiment, in the second week 4 series of 7 rises, and the last week 4 series of 10 rises, totaling 14 days of treatment.

\section{Morphological analysis}

After the experimental period, the animals of the acute group - 7 days, and chronic - 28 days, were submitted to euthanasia, previously anesthetized with intraperitoneal injection of ketamine and xylazine hydrochloride. After verifying the state of consciousness of the animal observed by the absence of motor response to tail clamping and interdigital folds, the right knee joints were dissected and reduced and fixed in Metacarn (70\% methanol, 20\% chloroform, 10\% glacial acetic acid) for 48 hours. After the pieces were fixed in 70\% alcohol for 15 days.

Tricloroacetic acid $5 \%$ for 7 days was used to descale the material. The material followed the routine histological procedure for paraffin inclusion. Slices in the sagittal plane were obtained using Olympus CUT 4055 microtome, $7 \mu \mathrm{m}$ thick, mounted on glass slides and stained with hematoxylin and eosin. The slides were analyzed under light microscope and photomicrographed under Olympus ${ }^{\circledR}$ DP71 (USA) and analyzed in the morphological aspects of the articular cartilage, synovial membrane and periarticular bone tissue corresponding to the periosteum region of the femur and tibia, right pelvic limb.

\section{Ethical aspects}

All experiments were conducted following the ethical precepts defined by the International Association for the Study of Pain (IASP, 1983), and approved by the Unioeste CEUA. Every effort was made to minimize the number of rats used in the experiment. 


\section{Results}

The knee joints of CG and CEG in the acute and chronic periods, showed characteristic morphology with the joint cartilage presenting smooth surface and organized in four normal cell layers in femur (Figure 2. A, B), and tibia (Figure 3. A, B) in the surface area showed higher cell density, clustered chondrocytes in horizontal positioning with a flat aspect. The intermediate zone denotes cells with a rounded pattern, isolated or in isogenic groups. In the region of the deep zone, a basophilic - tidemark line separates the calcified zone, with the cells organized in gaps.

In the LG animals, it is noted that the CFA-induced

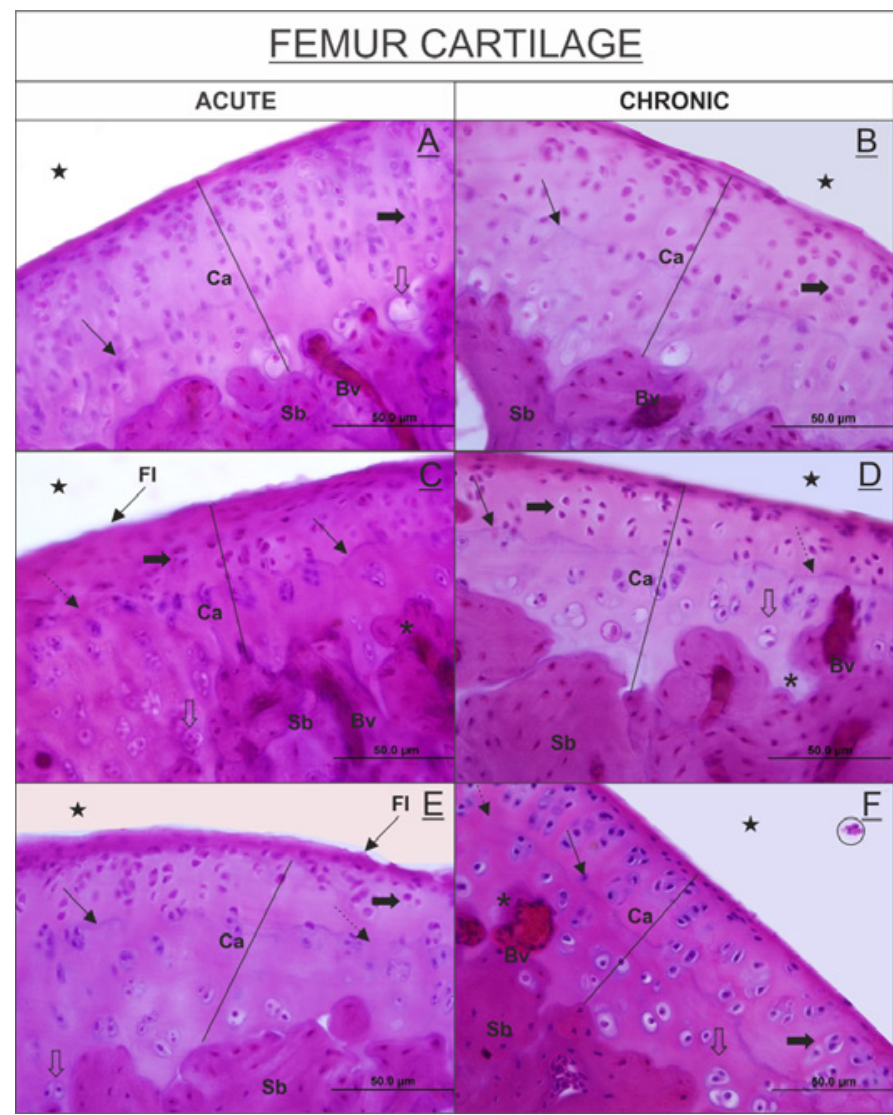

Figure 2. Photomicrographs of femoral joint cartilage, acute and chronic inflammatory periods.

Sagittal cut, hematoxylin and eosin stain in 1 magnification. CG (A, B) show normal aspects of joint cartilage (Ca), presence of tidemark (arrow), normal cellular organization (arrow filled) with higher density of chondrocytes in the surface area, subchondral bone (Os), blood vessels (Vs) with normal aspects, joint cavity (star) without inflammatory infiltration. In LG (C, D), changes in joint cartilage (Ca), discontinuity of tidemark (dotted arrow), invagination of subchondral bone (asterisk) and flocculations on the surface of the cartilage (arrow). The GLE in the acute group (E) is noted greater thickness of the cartilage, in the chronic inflammatory period $(F)$, the joint cartilage shows similarities with GC and tissue reorganization.

arthritis model had an effect on morphological changes in the femur, and tibia (Figure 2. C and D) and (Figure 3. C and D). Areas of thinner joint cartilage were found, verified with greater evidence in tibia, areas of flocculation, especially in the acute femur and tibia chronic group, discontinuity of the tidemark, cells arranged irregularly, greater invagination of subchondral bone.

In LEG animals (Figure 2. E, F), (Figure 3. E, F), submitted to injury and treated with physical exercise, areas with greater joint cartilage thickness were found in acute femur period, whereas the animals of the chronic inflammatory period show morphological similarities with CG with tissue reorganization.

The CG synovial membrane (Figure 4 . A and B), acute and chronic groups also presented with normal, two to three cell layers in the intima synovialis, and subintima with a predominance of adipose cells and unchanged blood vessels.

In animals belonging to the GL (Figure 4. C and D),

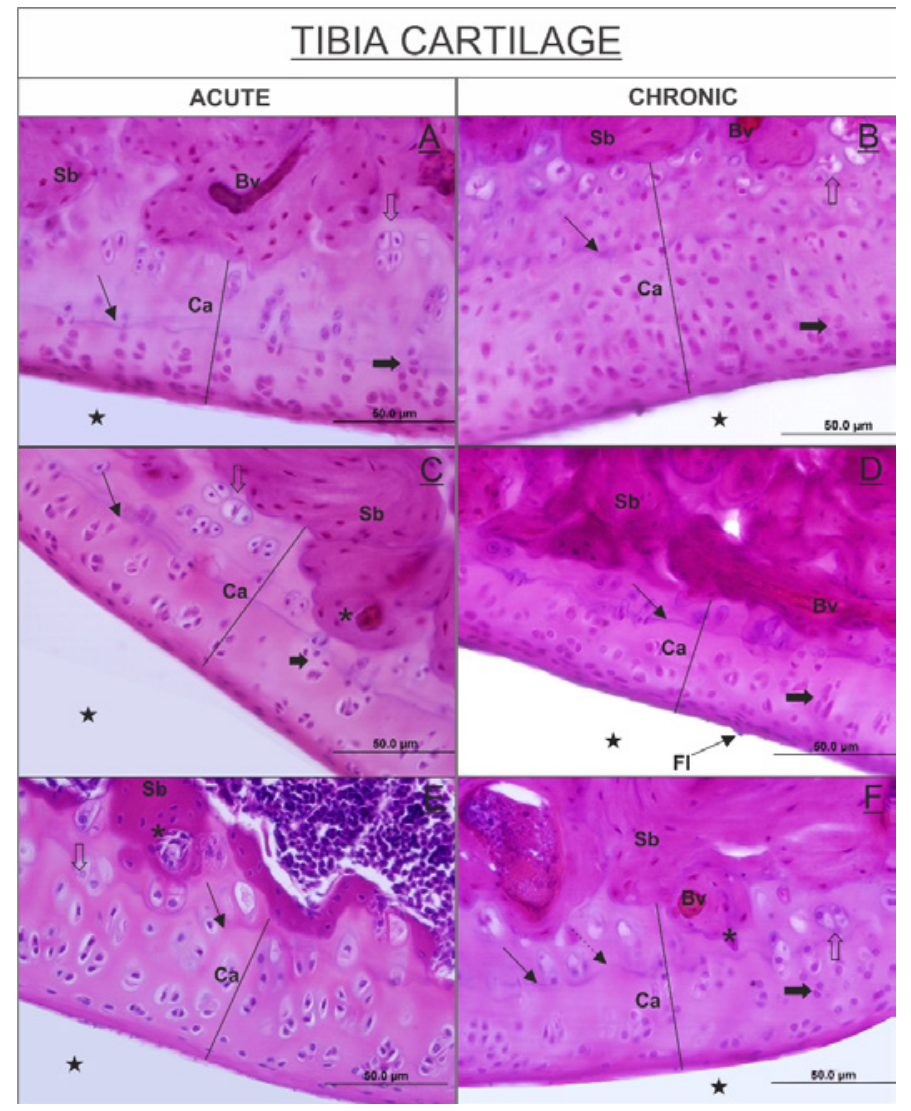

Figure 3. Photomicrographs of tibial joint cartilage, acute and chronic inflammatory periods.

Sagittal cut, hematoxylin and eosin stain in 1 magnification. CG (A, B) show normal aspects of joint cartilage (Ca), presence of tidemark (arrow), normal cellular organization (arrow filled) with higher density of chondrocytes in the surface area, subchondral bone (Os), blood vessels (Vs) with normal aspects, joint cavity (star) without inflammatory infiltration. In LG (C, D), changes in joint cartilage (Ca), with less thickness of cartilage in both acute and chronic group, discontinuity of tidemark (dotted arrow), invagination of subchondral bone (asterisk) and flocculations on the surface of the cartilage (arrow). The LEG $(E, F)$, note that the joint cartilage has similarities with CG and tissue reorganization.

the tissue denotes an intense inflammatory process with thickening of the synovial intima, disorganized in respect to the epithelial distribution of the synovocytes, substitution of fatty to fibrous connective tissue.

The animals treated with exercise (LEG) (Figure 4. $\mathrm{E}, \mathrm{F})$, the synovial membrane, the intima remained fibrous while the subintima presented a slight tissue 


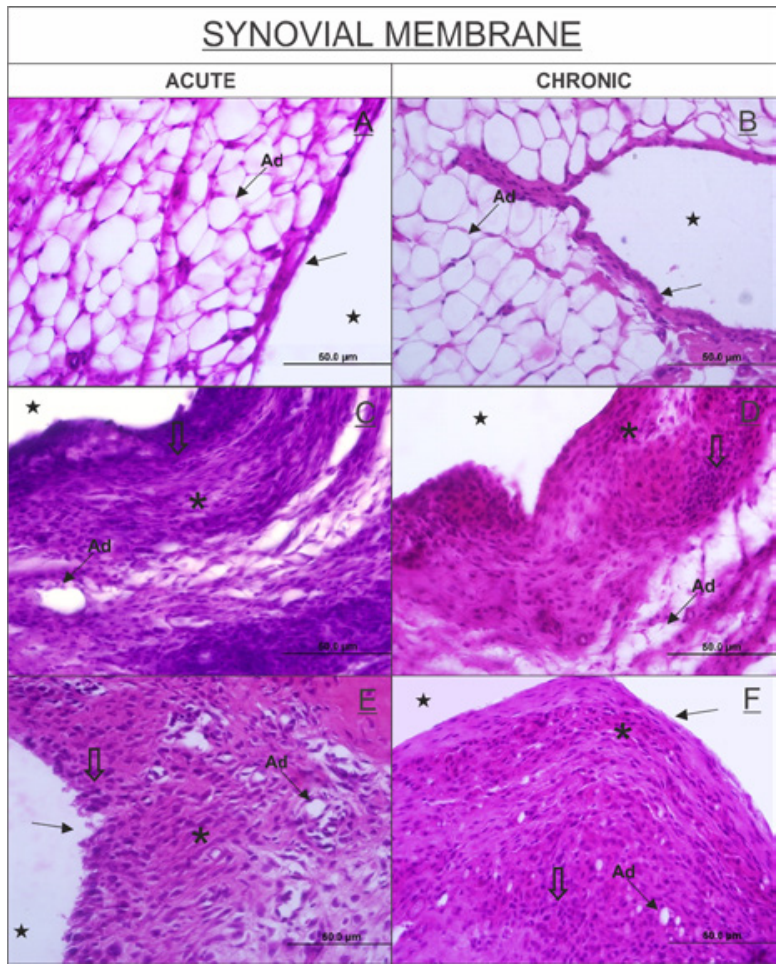

Figure 4. Photomicrographs of the synovial membrane acute and chronic inflammatory periods.

Sagittal cut, hematoxylin and eosin staining in 1 magnification. CG (A, B) shows normal aspects of the synovial membrane organized in two layers, the intima synovial (arrow), subintima organized with the presence of adipocytes (Ad), joint cavity (star) without inflammatory infiltration. In LG (C, D) inflammatory process tissue with thickening of the synovial intima and replacement of fat tissue by fibrous tissue in the subintima (asterisk). The animals of the LEG (E, F) intima synovial fibrous (arrow) with slight tissue recovery in the subintima and presence of adipocytes (Ad).

organization with little adipose tissue.

In the analysis of the periarticular bone region in femur (Figure 5) and tibia (Figure 6), the CG animals (A, B) denote normal aspects of bone tissue, with periosteum in its osteogenic and fibrous layers, and in the bone matrix there are no alterations in the blood vessels.

In the LG animals $(\mathrm{C}, \mathrm{D})$ morphological aspects characteristic of the inflammatory process are observed, with the presence of inflammatory cells, changes in the compact bone in the bone matrix to be characteristic of cancellous bone, gaps between the layers of the periosteum, and gaps in the bone matrix region in both femurs and tibia during the two inflammatory periods analyzed, with greater evidence in the femur acute group.

The LEG animals (E, F) presented morphological aspects similar to CG, showing bone remodeling, with repair of the bone matrix region, filling the gaps between the fibrous and osteogenic layers of the periosteum.

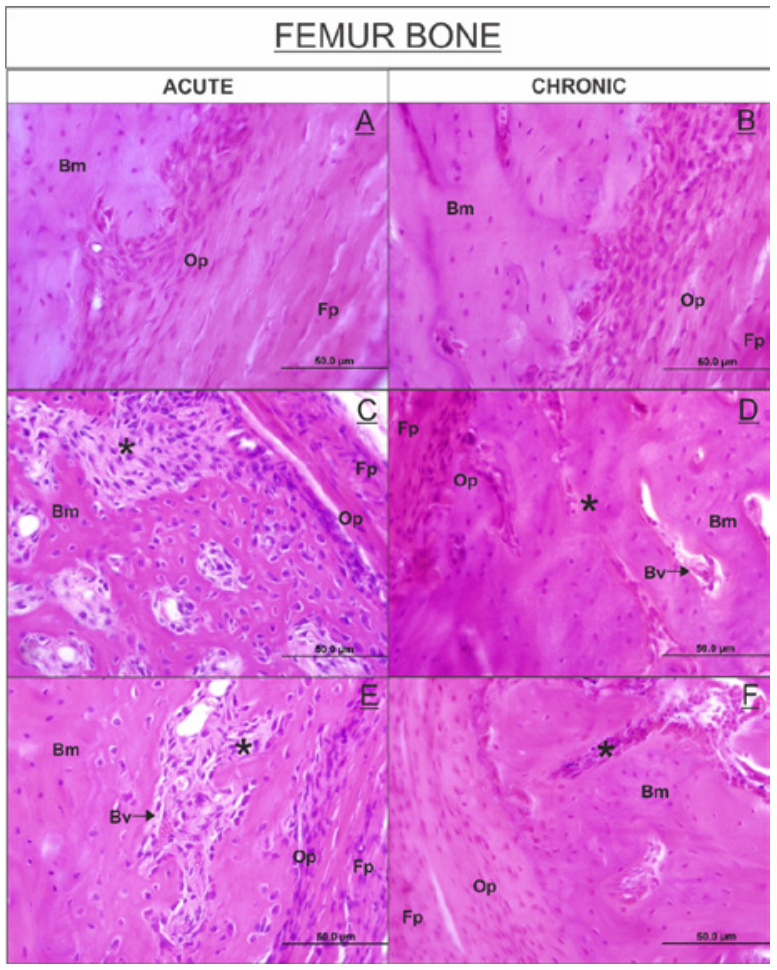

Figure 5. Photomicrographs of the periarticular femur, acute and chronic inflammatory periods.

Longitudinal cut, hematoxylin and eosin staining in 1 magnification. CG (A, B) denote normal aspects of bone tissue, periosteum in its osteogenic (Poo) and fibrous (Pof) layers, and bone matrix (Mo) with presence of blood vessels (Vs). LG (C, D), the presence of inflammatory cells and modification of the compact bone to characteristic of cancellous bone (asterisk), gaps in the bone matrix with greater evidence in femur acute group. In LEG (E, F) the animals denote bone tissue remodeling.

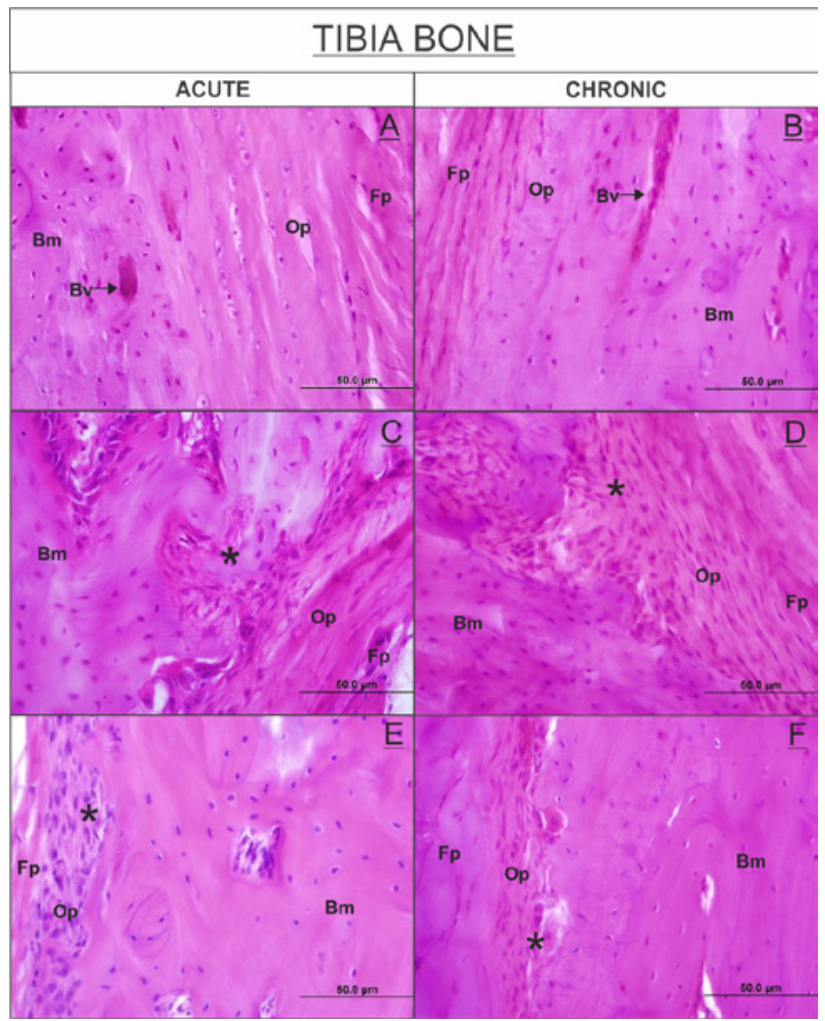

Figure 6. Photomicrographs of the tibia periarticular region, acute and chronic inflammatory periods.

Longitudinal cut, hematoxylin and eosin staining in 1 magnification. CG (A, B) denote normal aspects of bone tissue, periosteum in its osteogenic (Poo) and fibrous (Pof) layers, and bone matrix (Mo) with presence of blood vessels (Vs). LG (C, D), the presence of inflammatory cells and modification of the compact bone to characteristic of cancellous bone (asterisk) were found. In LEG (E, F) the animals show bone tissue remodeling with greater evidence in animals of the chronic group. 


\section{Discussion}

In the present study, it was found that the experimental model of HR induction using two CFA inoculations containing Mycobacterium butyricum alters the morphological aspects of the knee joint tissue of rats. Induction of RA in animals simulates the inflammatory signs that occur in humans, among them joint swelling, infiltration of inflammatory cells, hypersensitivity and histopathological changes ${ }^{13,14}$, that could be checked on the LG animals.

In the development of RA, initially the inflammatory process reaches the synovial membrane, denoting cellular hyperplasia, and evolves to tissue fibrosis ${ }^{3}$. In the present study, the LG animals presented synovitis, thickening of the intima and subintima layers and replacement of fatty to fibrous connective tissue in both the acute and chronic inflammatory periods were evidenced. Joint stiffness and reduced range of motion, due to less weight support as a result of the lesion, may be responsible for membrane thickening ${ }^{11,15}$. The animals treated in the LEG note discreet tissue organization although they still resembled LG.

Physical exercise stimulates joint movement and the mechanical stress that the cartilage absorbs, playing a beneficial role in cartilaginous metabolism. Adequate exercise levels act by stimulating angiogenesis, growth factors and production of type II collagen, and the reduction of exercise load is related to atrophy and disease progression in histological aspects ${ }^{16}$. In the present study, the animals treated with physical exercise showed restoration of morphological aspects in the articular cartilage, evidenced with more emphasis in the chronic inflammatory period of the disease. Movement restoration reduces joint stiffness promoting joint cartilage nutrition and consequent regeneration of this structure due to the chondroprotective effect exerted by physical exercise ${ }^{11}$.

Lange et al. postulate that an exercise program of moderate to high intensity with adequate orientation effectively improves the physical fitness of the individual with respect to aerobic capacity, muscle endurance, strength and dynamic balance in patients with $\mathrm{RA}^{9}$. The articular cartilage of LEG animals in the acute inflammatory period presents tissue remodeling and increased joint cartilage thickness. The relationship between physical activity and cartilage thickness results from the mechanism of mechanocellular transduction, due to the load the cartilage cells respond with increased proteoglycan, which favors the cartilage swelling ${ }^{17}$.
The diffusion of synovial fluid in the joint cavity is necessary due to the nutrition function of chondrocytes $^{18}$, and the climbing exercise on stairs seems to have favored improvement of this structure, with aspects of tissue repair of the articular cartilage.

The qualitative analysis of periarticular bone is little studied, but of great importance, due to the high rate of fractures that individuals with RA can develop during the course of the disease ${ }^{19-21}$. Periarticular bone loss results from excessive bone resorption and increased bone tissue formation, and the lack of repair is a consequence of suppression of osteoclast function ${ }^{22}$.

The LG animals in femur and tibia denote morphological aspects characteristic of inflammatory process, with modifications of compact bone tissue to characteristic of cancellous bone, and bone gaps. The RA induces periarticular osteoporosis, which is characterized by deterioration and decreased cortical bone quality, and trabecular bone loss, which induces periarticular bone fragility adjacent to the inflamed joints ${ }^{7,19,20,23 .}$

In the present study, the LEG animals that were treated with resistance exercise, presented morphological aspects similar to CG, showing bone remodeling, with repair of the bone matrix region. Shimomura et al. infer that exercise suppresses joint destruction by improving periarticular bone tissue, playing an important role in modulating proinflammatory cytokines, acting as a safe therapy that can be indicated for patients with RA from the early stage of the disease $\mathrm{e}^{24}$.

The effectiveness of exercise may be different depending on the phase of the RA, however active exercise during chronic phases in addition to decreasing the activity of the disease, can effectively inhibit the destruction of joint tissues ${ }^{25}$. The modality of treatment using climbing resistance exercise on stairs in this study, acted in a beneficial way in the reestablishment of the morphological parameters of the knee joint in the acute and chronic experimental period, thus indicating the benefit of exercise both in the early stages and during the disease.

\section{Conclusions}

Physical exercise has beneficial effects on the tissue recovery of the knee joint and periarticular bone tissue of rats submitted to an experimental rheumatoid arthritis model.

\section{References}

1. Hörnberg K, Sundström B, Innala L, Rantapää-Dahlqvist S, Wållberg-Jonsson S. Aerobic capacity over 16 years in patients with rheumatoid arthritis: Relationship to disease activity and risk factors for cardiovascular disease. PLoS One. 2017;12(12):1-16.

2. Vaks K, Sjöström R. Rheumatoid arthritis patients' experience of climate care. J Exerc Rehabil. 2015;11(6):337-44.

3. Macedo RBV, Kakehasi AM, de Andrade MVM. Ação da IL33 na artrite reumatoide: Contribuição para a fisiopatalogia. Rev Bras Reumatol. 2016;56(5):451-7.

4. Huang CC, Chiou CH, Liu SC, Hu SL, Su CM, Tsai CH, et al. Melatonin 
attenuates TNF- $\alpha$ and IL-1 $\beta$ expression in synovial fibroblasts and diminishes cartilage degradation: Implications for the treatment of rheumatoid arthritis. J Pineal Res. 2019;66(3):1-12.

5. Sudot-szopińska I, Kontny E, Maśliński W, Prochorec -sobieszek M, Kwiatkowska B, Zaniewicz -kaniewska K, et al. Patogeneza reumatoidalnego zapalenia stawów w badaniach radiologicznych. Część I: Powstawanie nacieków zapalnych w błonie maziowej. J Ultrason J Ultrason. 2012;12(12):202-13.

6. Zheng W, Lu X, Fu Z, Zhang L, Li X, Xu X, et al. Identification of candidate synovial membrane biomarkers after Achyranthes aspera treatment for rheumatoid arthritis. Biochim Biophys Acta Proteins Proteomics. 2016;1864(3):308-16.

7. Ito H, Moritoshi F, Hashimoto M, Tanaka M, Matsuda S. Control of articular synovitis for bone and cartilage regeneration in rheumatoid arthritis. Inflamm Regen. 2018;38(7):1-11.

8. Caplazi P, Baca M, Barck K, Carano RAD, DeVoss J, Lee WP, et al. Mouse Models of Rheumatoid Arthritis. Vet Pathol. 2015;52(5):81926.

9. Lange E, Kucharski D, Svedlund S, Svensson K, Bertholds G, Gjertsson I, et al. Effects of Aerobic and Resistance Exercise in Older Adults With Rheumatoid Arthritis: A Randomized Controlled Trial. Arthritis Care Res. 2019;71(1):61-70.

10. Luan X, Tian X, Zhang H, Huang R, Li N, Chen P, et al. Exercise as a prescription for patients with various diseases. J Sport Heal Sci. 2019;8(5):422-41.

11. Kunz RI, Silva LI, Costa JRG da, Soares CLR, Bertolini GRF, Brancalhão RMC, et al. Alterações histomorfométricas na articulação do joelho de ratos Wistar após remobilização em meio aquático. Fisioter e Pesqui [Internet]. 2015;22(3):317-24. Available from: http://www.scielo.br/scielo.php?script=sci_ arttext\&pid=S1809-29502015000300317\&lng=pt\&nrm=iso

12. Neves M, Retameiro ACB, Tavares AL de F, Reginato A, Menolli RA, Leal TS da S, et al. Physical exercise and low-level laser therapy on the nociception and leukocyte migration of Wistar rats submitted to a model of rheumatoid arthritis. Lasers Med Sci. 2019:35(1):1277-87.

13. Gomes RP, Bressan E, da Silva TM, Gevaerd M da S, Tonussi CR, Domenech SC. Efeitos de um minuto e dez minutos de deambulação em ratos com artrite induzida por adjuvante completo de Freund sobre os sintomas de dor e edema. Rev Bras Reumatol. 2014;4:4-10. 14. Gomes RP, Bressan E, Morgana T, Gevaerd S, Tonussi CR, Domenech SC. Standardization of an experimental model suitable for studies on the effect of exercise on arthritis Padronização de modelo experimental adequado a estudos do efeito do exercício na artrite. Einstein. 2013;11(55 48):76-82.
15. Vieira L, Lovison K, Kunz RI, Antunes JS, Bertolini GRF, Brancalhão RMC, et al. Resistance exercise recovers the structure of cartilage and synovial membrane of the ankle joint of rats after sciatic compression. Mot Rev Educ Física. 2017;23(3):1-8.

16. Takahashi I, Matsuzaki T, Kuroki H, Hoso M. Joint unloading inhibits articular cartilage degeneration in knee joints of a monosodium iodoacetate-induced rat model of osteoarthritis. Osteoarthr Cartil. 2019;27(7):1084-93.

17. Roos EM, Dahlberg L. Positive effects of moderate exercise on glycosaminoglycan content in knee cartilage: A four-month, randomized, controlled trial in patients at risk of osteoarthritis. Arthritis Rheum. 2005;52(11):3507-14.

18. Hayer S, Bauer G, Willburger M, Sinn K, Alasti F, Plasenzotti $\mathrm{R}$, et al. Cartilage damage and bone erosion are more prominent determinants of functional impairment in longstanding experimental arthritis than synovial inflammation. DMM Dis Model Mech. 2016;9(11):1329-38.

19. Abasolo L, Ivorra-Cortes J, Leon L, Jover JA, Fernández-Gutiérrez $\mathrm{B}$, Rodriguez-Rodriguez L. Contribution of the bone and cartilage/ soft tissue components of the joint damage to the level of disability in rheumatoid arthritis patients: a longitudinal study. Clin Rheumatol. 2019;38(3):691-700.

20. Brown JM, Ross E, Desanti G, Saghir A, Clark A, Buckley C, et al. Detection and characterisation of bone destruction in murine rheumatoid arthritis using statistical shape models. Med Image Anal. 2017;40:30-43.

21. Gao F, Yuan Q, Cai P, Gao L, Zhao L, Liu M, et al. Au Clusters Treat Rheumatoid Arthritis with Uniquely Reversing Cartilage/Bone Destruction. Adv Sci. 2019;6(7).

22. Shim J hyuck, Stavre Z, Gravallese EM. Bone Loss in Rheumatoid Arthritis: Basic Mechanisms and Clinical Implications. Calcif Tissue Int [Internet]. 2018;102(5):533-46. Available from: http://dx.doi. org/10.1007/s00223-017-0373-1

23. Shimizu T, Takahata M, Kimura-Suda H, Kameda Y, Endo K, Hamano $\mathrm{H}$, et al. Autoimmune arthritis deteriorates bone quantity and quality of periarticular bone in a mouse model of rheumatoid arthritis. Osteoporos Int. 2017;28(2):709-18.

24. Shimomura S, Inoue H, Arai $\mathrm{Y}$, Nakagawa S, Fujii $\mathrm{Y}$, Kishida T, et al. Treadmill running ameliorates destruction of articular cartilage and subchondral bone, not only synovitis, in a rheumatoid arthritis rat model. Int J Mol Sci. 2018;19(6).

25. Fujii Y, Inoue H, Arai Y, Shimomura S, Nakagawa S, Kishida T, et al. Treadmill running in established phase arthritis inhibits joint destruction in rat rheumatoid arthritis models. Int J Mol Sci. 2019;20(20):1-13.
Received: May 10, 2021

Accepted: June 20, 2021
Corresponding author

Morgana Neves

E-mail: morgananeves26@gmail.com 